\title{
Kinetics of Pyrolysis of Date Kernels
}

\author{
S.T. Aly, I. A. Ibrahim, M.F. Abadir
}

\begin{abstract}
The kinetics of pyrolysis of ground date kernels was investigated using thermogravimetric analysis in order to provide the necessary information for proper biochar formation and bioreactor design. Pyrolysis was carried out at heating rates of 5 , 10,15 and $20^{\circ} \mathrm{C}$. $\mathrm{min}^{-1}$ in a flow of nitrogen. One main DTG peak was obtained that corresponded to formation of bio-char. A second diffuse peak corresponds to constant rate cracking of the char formed and complete elimination of carbon leaving an ash residue. The composition of biochar was determined using EDX. Four different methods were used to follow up the kinetics of the three steps, namely, the Kissinger, the Flynn-Wall-Ozawa, the Coats-Redfern methods and multi-regression analysis. The activation energy of the main decomposition step was determined and the values obtained using different kinetic models compared. The decomposition step simply followed first order kinetics.
\end{abstract}

Keywords: date, kernels, kinetics, Pyrolysis

\section{I INTRODUCTION}

$\mathrm{B}_{\mathrm{e}}$ ecause of the fact that fossil fuels reserves are limited and their rate of depletion is ever growing [1], research was focused on sources of alternative energy. One solution that has gained importance in the last few years is the production of biomass from vegetable sources to be used as fuel. This is rapidly taking its share as a member of the production of renewable energy in the world energy system [2]. In particular, vegetable wastes have raised much interest because of their availability, cheap cost and the fact that their use are beneficial from both economic and environmental viewpoints. The pyrolysis of such wastes has been the focus of many research work using diverse materials such as rice straw [3], orange peels [4], olive kernels [5], banana peels [6] and a lot of other wastes $[7,8]$. The relative proportion of the products from pyrolysis depend, among other factors on the rate of heating [9], a slow rate favoring the formation of biochar [10]. Date pits are also called pips, stones, kernels, or seeds depending on the variety and quality grade; the kernel

Revised Manuscript Received on February 05, 2020.

* Correspondence Author

S.T. Aly*, Chemical Engineering Department, Egyptian Academy for Engineering and Advanced Technology (EA\&EAT), affiliated to

Ministry of Military Production, Cairo, Egypt. Email: Sohair@eaeat.edu.eg

I. A. Ibrahim, Material Science Department,Central Metallurgical Research Institute, Helwan, Egypt., Email: ibrahimahmedcmrdi01@gmail.com

M. F. Abadir, Chemical Engineering Departnent, Cairo university, Giza, Egypt.. Email: Mfabadir@gmail.com

(C) The Authors. Published by Blue Eyes Intelligence Engineering and Sciences Publication (BEIESP). This is an open access article under the CC BY-NC-ND license (http://creativecommons.org/licenses/by-nc-nd/4.0/) represent $6-12 \%$ of the date of its total weight in the ripe stage. The approximate composition is displayed in

"Table. I", while the elemental analysis on samples of date kernels of Iglani dates (Egypt) is shown in ("Table. II").

Table -I: Approximate composition of the date stone on dry basis [11]

\begin{tabular}{|l|c|}
\hline Component & Weight \% \\
\hline Cellulose & 32.77 \\
\hline Hemicellulose & 30.2 \\
\hline Lignin & 37.03 \\
\hline
\end{tabular}

Table- II: Elementary analysis of date kernels [11]

\begin{tabular}{|l|c|}
\hline Component & Weight \% \\
\hline $\mathrm{C}$ & 47.2 \\
\hline $\mathrm{H}$ & 6.8 \\
\hline $\mathrm{N}$ & 2.9 \\
\hline $\mathrm{S}$ & 0 \\
\hline $\mathrm{O}$ & 37.9 \\
\hline $\mathrm{ash}$ & 5.2 \\
\hline
\end{tabular}

An early study by Salem et al [12] using TG and DTA revealed that the decomposition of date kernels follows a first order reaction of activation energy $=8.17 \mathrm{~kJ} \cdot \mathrm{mol}^{-1}$, too low a value compared to those obtained in later works. Waluyo, et al [13] studied the catalyzed intermediate pyrolysis of palm kernels shell under flowing of nitrogen at the rate of 200 $\mathrm{ml} / \mathrm{min}$ with heating rate of $75^{\circ} \mathrm{C} / \mathrm{min}$ and different temperatures 400,500 , and $600^{\circ} \mathrm{C}$. It was found that the yield of gaseous products increased with temperature while it decreased for char. The yield of pyrolysis products of oil, water, char, gaseous at $600^{\circ} \mathrm{C}$ were $39 \%, 8 \%, 28 \%$ and $25 \%$, respectively. The yield of the produced tar using a modified zeolite catalyst was 33\%. The basic constituent of bio-oil (tar) was a phenolic group while the content of acetic acid was reduced in bio-oil (tar) due to the presence of zeolite. On the other hand, Nasser et al [14] applied thermal decomposition with heating rate $10^{\circ} \mathrm{C} / \mathrm{min}$ in nitrogen medium on different parts of palm date. The TGA and DTG curves of the date palm residues displayed that in most cases complete thermal decomposition took place below $500^{\circ} \mathrm{C}$. All DTG curves displayed two peaks corresponding to the decomposition of hemicellulose and cellulose. They stated that the decomposition of lignin took place over a wide range of temperatures up to $900^{\circ} \mathrm{C}$ although the decomposition stages of the three components strongly overlapped. The DTG curves indicated that the maximum rate of weight loss occurred from $228^{\circ} \mathrm{C}$ to $512^{\circ} \mathrm{C}$ according to the particular part investigated. Also, Adhityatama et al [15] studied the pyrolysis characteristics of palm date shell using a thermogravimetric analyzer (TG\DTA). 


\section{Kinetics of Pyrolysis of Date Kernels}

The heating rate was $10{ }^{\circ} \mathrm{C} / \mathrm{min}$ and the temperature range was $25-800^{\circ} \mathrm{C}$, with nitrogen as the carrier gas. The study disclosed that the decomposition could be divided into two stages with respective activation energies of $172.86 \mathrm{~kJ} \cdot \mathrm{mol}^{-1}$ $\left(200-322^{\circ} \mathrm{C}\right)$ and $164.23 \mathrm{~kJ} \mathrm{~mol}^{-1}\left(322-384^{\circ} \mathrm{C}\right)$ after which char was formed. On the other hand, Surahmanto et al [16], on investigating palm shell waste using a distributed activation energy model obtained values of activation energy for the overall decomposition process ranging from 59.36 to $170.30 \mathrm{~kJ} \mathrm{~mol}^{-1}$ depending on the level of conversion. Recently, Hussain et al [17] investigated the thermal behavior of palm kernels by thermogravimetric analysis. Applying the Kissinger method, they were able to determine the activation energies for the decomposition of hemicellulose (24.65 $\left.\mathrm{kJ} . \mathrm{mol}^{-1}\right)$, cellulose $\left(78.98 \mathrm{~kJ} \mathrm{~mol}^{-1}\right)$ and lignin (183.07 $\left.\mathrm{kJ} \mathrm{mol}^{-1}\right)$. The first two values heavily contrast with the reported results of Adhityatama et al [15]

In the present work, four different methods were used to disclose the kinetics of decomposition of ground date kernels, namely, the Kissinger, Flynn-Wall-Ozawa, the Coats-Redfern methods and a multi-regression analysis technique.

\section{MATERIALS AND METHODS}

1. Date kernels were crushed then finely ground in an agate mortar and the particle size distribution obtained using a standard screen set in accordance with ASTM 136-05 [18].

2. The fine powder was then placed in an alumina crucible in a thermal analysis apparatus (TG-DTG) type Shimadzu $50 / 51$. This was operated at four different heating rates, namely 5, 10, 15 and $20^{\circ} \mathrm{C} . \mathrm{min}^{-1}$ in a continuous flow of nitrogen as the rate of $50 \mathrm{ml} \cdot \mathrm{min}^{-1}$.

3. Four different methods were then applied to obtain the activation energy of decomposition of the waste and the kinetic mechanism of reaction.

4. The high calorific value of dried ground kernels was measured using a bomb calorimeter type Parr 6200.

5. The formed biochar was examined using Energy Dispersive X-ray analysis (EDX) in an apparatus of type SEM-EDX Quanta FEG 250.

\section{RESULTS AND DISCUSSION}

\section{A. Particle size distribution of ground date kernels}

"Fig. 1"shows the particle size distribution of the ground powder. The median particle size D50 equals $0.23 \mathrm{~mm}$..

\section{B. Calorific value}

For any potential use as biofuel, the net calorific value of the ground powder was determined in a bomb calorimeter and found to equal $19420 \mathrm{~kJ}_{\mathrm{kg}} \mathrm{kg}^{-1}$.

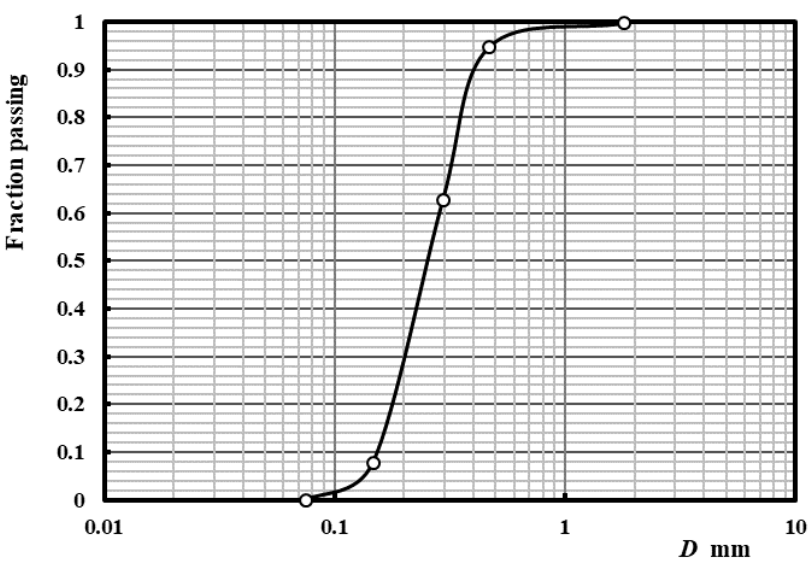

\section{Fig .1. PARTICLE SIZE DISTRIBUTION OF GROUND KERNELS.}

\section{Thermogravimetric curves}

The thermogravimetric TG/DTG curves were obtained at four different rates: $5,10,15$ and $20^{\circ} \mathrm{C} . \mathrm{min}^{-1}$. Temperature was raised from 25 to $900^{\circ} \mathrm{C}$, while nitrogen was flown at the rate of $50 \mathrm{ml} \cdot \mathrm{min}^{-1}$. Only one such diagram is shown in "Fig. 2 "for the results at a heating rate of $15^{\circ} \mathrm{C} \cdot \mathrm{min}^{-1}$, the results at other rates being similar with peak temperatures increasing with increased heating rate. All four curves reveal the presence of one major DTG peak corresponding to the elimination of hemicellulose following the slight decrease in weight ending at about $150^{\circ} \mathrm{C}$ corresponding to the loss of physical moisture. At the end of the peak at $340^{\circ} \mathrm{C}$, two small shoulders appear corresponding to the decomposition of cellulose and lignin ending at $455^{\circ} \mathrm{C}$, a fact that was also reported by Nasser et al [14]. A linear portion on the TG curves follows that shoulder to reach a quasi-total loss in weight at temperatures above $800^{\circ} \mathrm{C}$. The decomposition of hemicellulose, cellulose and lignin ends up by the formation of char. This gradually loses its volatile components at constant rate as evidenced by the almost constant DTG value prevailing up to $900^{\circ} \mathrm{C}$. The ash residue left amounts to about $4 \%$ of the initial mass.

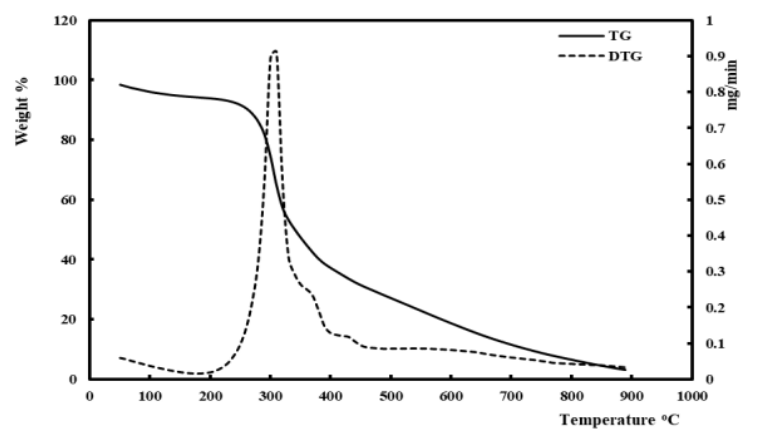

Fig. 2. TG/DTG curves for date kernels at $15^{\circ} \mathrm{C} \cdot \mathrm{min}^{-1}$

\section{Conversion - temperature curves}

The values of conversion corresponding to a remaining mass $m$ were calculated at all four heating rates for the main decomposition step using the definition:

$$
\alpha=\frac{m_{i}-m}{m_{i}-m_{f}}
$$

Where: $m_{i}$ is the initial mass and $m_{f}$ the mass at the termination of the step. 
The conversion - temperature curves are reported in "Fig. 3"

\section{E. Kinetics of major decomposition step}

The kinetics of the major decomposition step was investigated using two non-model methods, namely the Kissinger and the Flynn-Wall-Ozawa methods and one model type method: The Coats-Redfern method. This latter method not only discloses the value of activation energy but can also predict the most probable reaction mechanism. Besides, a fourth method relying on a basic kinetic equation was also used.

\section{1) Results using the Kissinger method}

This method relies on plotting values of $\ln \frac{\beta}{T_{p}^{2}}$ against $\frac{1}{T_{p}}$ where $T_{p}$ represents the peak DTG temperatures of the step under investigation. The linear plot obtained has a slope $=$ $-\frac{E}{R}$ from which the apparent activation energy $E$ can be calculated [19].

"Table. III", displays the values of the peak temperatures $\left(T^{\circ} \mathrm{C}\right)$ of the decomposition step as function of the heating rate. These values were accurately obtained from the printout generated by the thermal analysis apparatus.

On the other hand, "Fig.4", shows the Kissinger plot for the decomposition step. The numerical value of the slope, as determined from the straight line obtained $=19417$, corresponding to an activation energy $=161.4 \mathrm{~kJ} \cdot \mathrm{mol}^{-1}$. This value agrees with that obtained by Adhityatama et al [15] who determined a close value of activation energy of

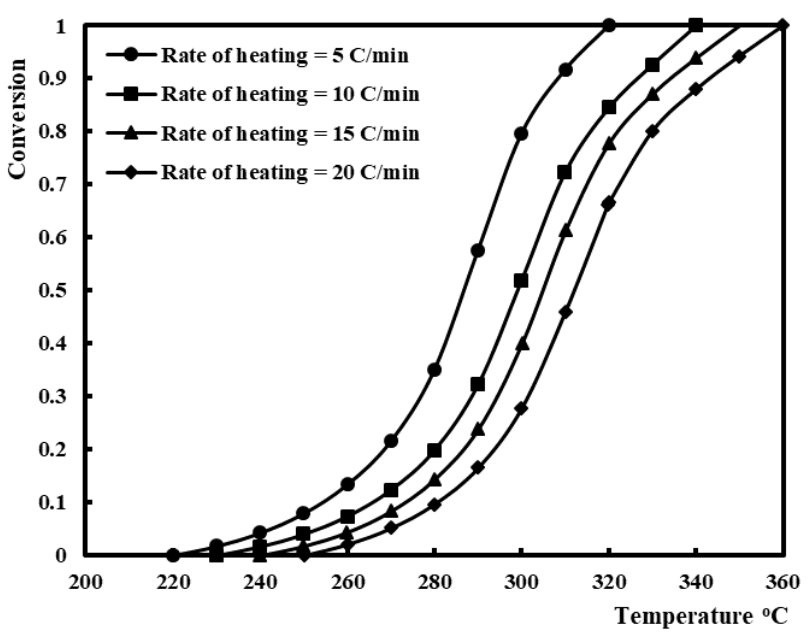

Fig. 3. Conversion - temperature curves for the decomposition of date kernels

$172.86 \mathrm{~kJ} \mathrm{~mol}^{-1}$. Also, the present value is fairly close to that determined by Hussain et al [17] who obtained a value of

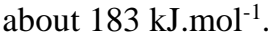

Table-III: Peak temperatures for the main decomposition step of date kernels

\begin{tabular}{|l|r|r|r|r|}
\hline $\begin{array}{l}\text { Rate of } \\
\text { heating } \\
\boldsymbol{\beta}\end{array}$ & $\mathbf{5}$ & $\mathbf{1 0}$ & $\mathbf{1 5}$ & $\mathbf{2 0}$ \\
${ }^{\mathbf{0}} \mathbf{C} . \mathbf{m i n}^{-1}$ & & & & \\
\hline $\boldsymbol{T}_{\boldsymbol{p}}{ }^{\mathbf{0}} \mathbf{C}$ & 289.7 & 300.5 & 305.4 & 312.4 \\
\hline
\end{tabular}

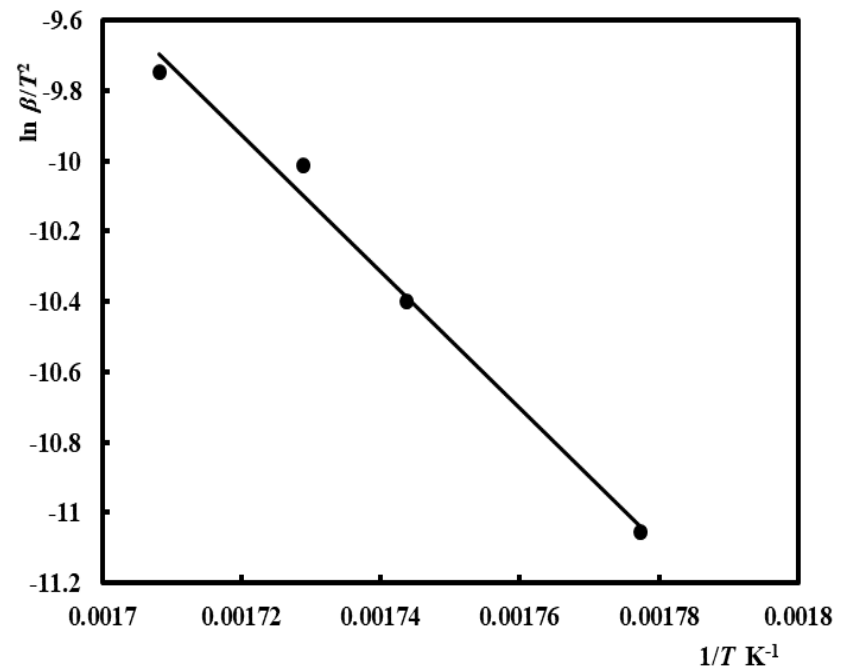

Fig.4. Kissinger plot for the main decomposition step of date kernels

2) Results using the Flynn-Wall-Ozawa (FWO) iso-conversional method

In this method, the temperatures ( $T \mathrm{~K}$ ) corresponding to constant values of conversion $(\alpha)$ are determined at each rate of heating $\left(\beta{ }^{\circ} \mathrm{C} \cdot \mathrm{min}^{-1}\right)$. Plots of $\ln \beta$ against $\frac{1}{T}$ are then carried out at the chosen values of conversion. The plots should yield straight lines of slope $=-\frac{1.052 E}{R}$ [20]. This allows determining the value of $E$. The plots are illustrated in "Fig.5". The calculated values of apparent activation energy $E$ are tabulated below and are seen to be very close as evidenced by the parallel nature of the straight lines obtained.

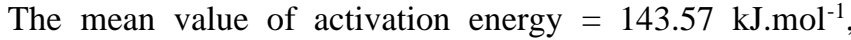
which is close to the value obtained on applying the Kissinger method.

Table-IV: Activation energy for the decomposition of date kernels (FWO method)

\begin{tabular}{|l|c|c|c|c|}
\hline $\begin{array}{l}\text { Conversion } \\
\boldsymbol{\alpha}\end{array}$ & $\mathbf{0 . 4}$ & $\mathbf{0 . 5}$ & $\mathbf{0 . 6}$ & $\mathbf{0 . 7}$ \\
\hline E kJ.mol $^{-1}$ & 144.3 & 145 & 144.6 & 140.4 \\
& & & & \\
\hline
\end{tabular}




\section{Kinetics of Pyrolysis of Date Kernels}

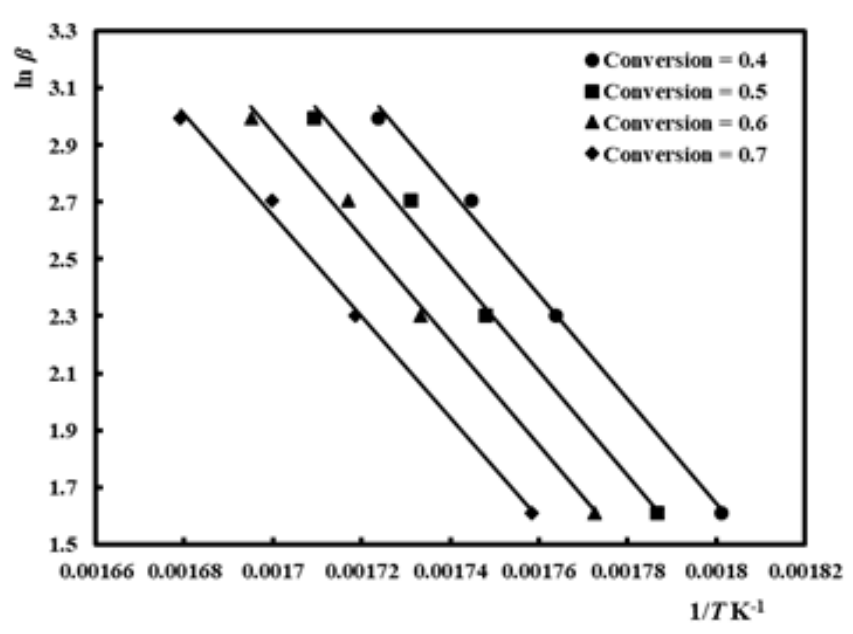

Fig. 5. F-W-O plot for the main decomposition step of date kernels

\section{3) Results using the Coats-Redfern method [21]}

While the latter non-model methods didn't provide any information about the probable mechanism of reaction, the present method has the merit to disclose that mechanism. In this method, it is first necessary to assume a certain reaction kinetic function $g(\alpha)$ defined by:

$k t=g(\alpha)$

Where, $k$ is the reaction rate constant $\left(\mathrm{min}^{-1}\right)$.

The different forms of the function $g(\alpha)$ have been compiled by Khawam et al [22] for different reaction mechanisms and particle shapes.

After choosing probable kinetic functions, a plot of $\ln \frac{g(\alpha)}{T^{2}}$ against $\frac{1}{T}$ is performed using the chosen forms of $g(\alpha)$. The closest linear plot, as revealed by the highest determination coefficient $\left(\mathrm{R}^{2}\right)$ discloses the probable form of $g(\alpha)$ and hence the reaction mechanism.

In the reaction at hand, the best fits were obtained for the four heating rates when a first order reaction was assumed, following the law:

$g(\alpha)=\ln (1-\alpha)=k t$

"Fig.6", reveals that the four straight lines are almost parallel, indicating close values of activation energy. "Table.V", shows these values who yielded an average value of about $143 \mathrm{~kJ} \mathrm{~mol}^{-1}$, a value identical to that obtained by the FWO method while being slightly lower than that calculated by the Kissinger method. The fact that the reaction follows first order kinetics agrees with the early work of Salem et al [12] although the value obtained by these authors is much lower than the present one (8.17 compared to 143 $\mathrm{kJ} \cdot \mathrm{mol}^{-1}$ ).

Table- V: Activation energy for the decomposition of date kernels (Coats-Redfern)

\begin{tabular}{|l|c|c|c|c|}
\hline $\begin{array}{l}\text { The Rate of heating } \\
\text { B C.min }\end{array}$ & 5 & 10 & 15 & 20 \\
\hline$E$ kJ.mol & & & & \\
\hline
\end{tabular}

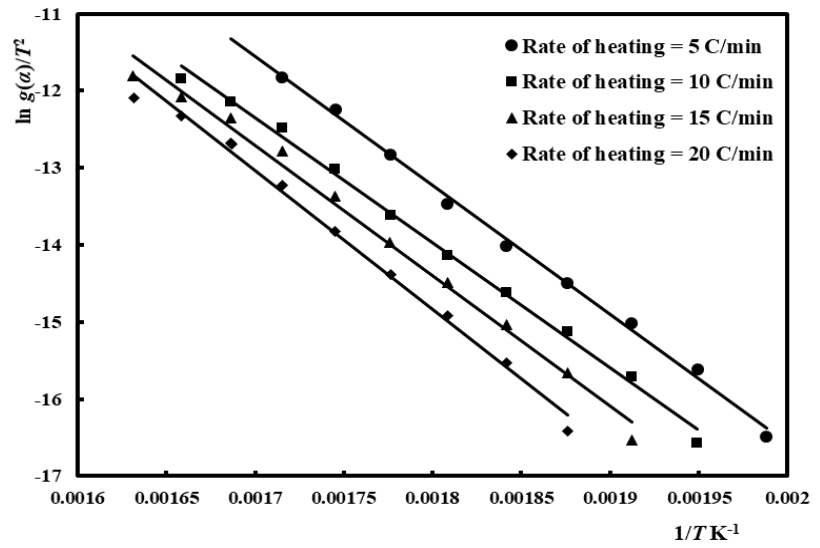

Fig. 6. : Coats-Redfern plot for the main decomposition step of date kernels

4) The use of a multi-regression method [23]

A general form of the rate of reaction can be expressed as follows:

$\frac{d m}{d t}=A e^{-\frac{E}{R T}} \cdot(1-\alpha)^{n}$

Where, $n$ is the apparent order of reaction.

Taking logarithms of both sides, the equation reads:

$\ln \frac{d m}{d t}=\ln A-\frac{E}{R T}+n \cdot \ln (1-\alpha)$

(5)

For a decomposition step, the remaining mass of solid $(m)$ and the corresponding temperature $(T)$ can be obtained from the scroll sheet supplied by the thermal analyzer. The conversion $(\alpha)$ can then be calculated from equation (1), while the value of $\frac{d m}{d t}$ can be readily obtained from the DTG reading corresponding to that temperature. This way, a multi-linear regression equation can be obtained relating ln $\frac{d m}{d t}$ to $1 / T$ and $\ln (1-\alpha)$. The regression coefficients of these two variables enable to obtain the activation energy $E$ and the apparent order of reaction $n$. This has been carried out using the DATA ANALYSIS module available on EXCEL. The results obtained at each heating rate are presented in "Table.VI". They show that the values of activation energies obtained at different heating rates are

comparable with a mean value of $135.3 \mathrm{~kJ}_{\mathrm{mol}}{ }^{-1}$, a value slightly lower than that determined by the three other methods.

Table-VI: Apparent order of reaction and Activation energy for the main decomposition step of date kernels (Multi-linear regression method

\begin{tabular}{|l|c|c|c|c|}
\hline $\begin{array}{l}\text { Rate of heating } \beta \\
{ }^{\circ} \mathrm{C} \cdot \mathrm{min}^{-1}\end{array}$ & 5 & 10 & 15 & 20 \\
\hline$n$ & 1.00 & 1.11 & 1.23 & 1.19 \\
\hline$E$ kJ.mol & & & & \\
\hline
\end{tabular}




\begin{tabular}{|l|l|l|l|l|}
\hline $\begin{array}{l}\text { Determination } \\
\text { coefficient } \mathrm{R}^{2}\end{array}$ & 0.958 & 0.951 & 0.946 & 0.938 \\
\hline
\end{tabular}

Also, the values of $n$ are fairly close to unity, suggesting a first order reaction, a result similar to that obtained on applying the Coats-Redfern method.

\section{5) Effect of heating rate on the formation of bio-char}

The formation of biochar is associated with the termination of the decomposition steps. Following the results obtained, this occurs at temperatures depending on the heating rate used to run the bioreactor. "Table.VII" shows the dependence of formation temperature and the time required to reach it on the heating rate. These data were used to deduce an empirical equation, with high degree of accuracy that enables predicting the time ( $\tau$ min.) required for biochar to form from ground date kernels as function of heating rate $\left(\beta^{\circ} \mathrm{C} \cdot \mathrm{min}^{-1}\right)$.

$$
\tau=350.82 \beta^{-0.92} \quad\left(\mathrm{R}^{2}=0.999\right)
$$

Table- VII: Dependence of temperatures and time of biochar formation from date kernels on heating rate

\begin{tabular}{|l|c|c|c|c|}
\hline$\beta^{\circ} \mathrm{C} \cdot \mathrm{min}^{-1}$ & 5 & 10 & 15 & 20 \\
\hline$T^{\circ} \mathrm{C}$ & 427 & 442 & 456 & 477 \\
\hline$t$ min & 64 & 32.94 & 23.26 & 18 \\
\hline
\end{tabular}

On the other hand, Figure (6) illustrates the EDX results obtained on analyzing the char product obtained on heating a specimen of ground date kernels to $450^{\circ} \mathrm{C}$ in a muffle furnace under nitrogen flow at a heating rate of $10^{\circ} \mathrm{C} \cdot \mathrm{min}^{-1}$. In addition, "Table. VIII") shows elementary analysis and it can be noticed that the sample is very rich in carbon, its percentage exceeding 88 .

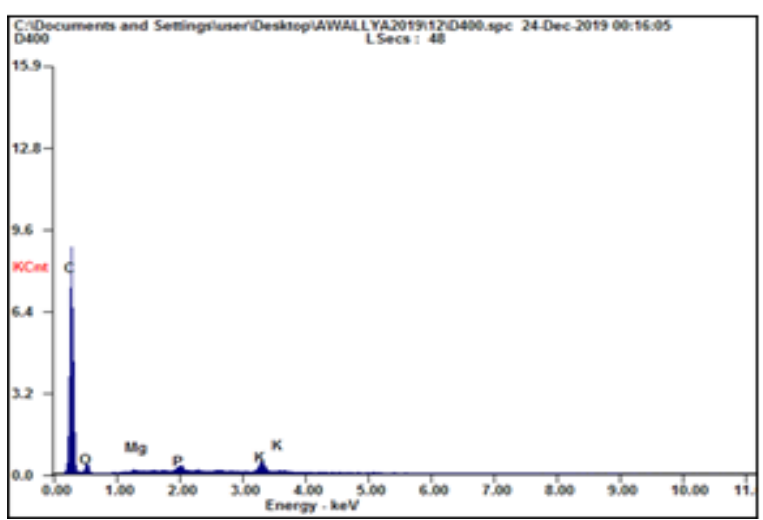

Fig. 7. EDX results for bio-char obtained from date kernels

Table- VIII: Elementary analysis of bio-char obtained from date kernels

\begin{tabular}{|l|c|c|}
\hline Element & $\mathbf{W t} \%$ & At\% \\
\hline $\mathbf{C}$ & 88.79 & 91.93 \\
\hline $\mathbf{O}$ & 9.65 & 7.5 \\
\hline $\mathbf{P}$ & 0.18 & 0.09 \\
\hline $\mathbf{K}$ & 0.4 & 0.16 \\
\hline
\end{tabular}

\section{CONCLUSION}

The thermal analysis of ground date kernels was carried out in a stream of nitrogen at four heating rates, namely 5, 10, 15 and $20^{\circ} \mathrm{C} \cdot \mathrm{min}^{-1}$. A main DTG peak appeared followed by two minor peaks ending with the formation of char. The composition of that latter was rich in carbon making it an excellent candidate as solid fuel.

The activation energy of the main decomposition step was determined by four different methods which gave fairly close values ranging from about 135 to $160 \mathrm{~kJ} . \mathrm{mol}-1$, while that step was proved to follow first order kinetics using the Coats-Redfern model and a multi-linear regression method. An empirical expression was proposed to predict the time required for biochar formation as a main parameter in designing a suitable bioreactor.

\section{REFERENCES}

1. E. Agbontalor), "Overview of various biomass energy conservation routes", Am. Eurasian J. Agric. Environ, 2007, 2: 662 - 671.

2. BP Global , "BP Statistical review of world energy", 2018.

3. J. Park., Y. Lee., C., Ryu ., K-Y Park, "Slow pyrolysis of rice straw: Analysis of products properties, carbon and energy yields" Biores. Tech, 2014, 155: 63 - 70

4. D. Kwon., J.Ik.Oh, S.S. Lam ., D.H. Moon ., E.E. Kwon, “Orange peel valorization by pyrolysis under the carbon dioxide environment" Biores. Tech, 2019, 285: 121356

5. M.F. Abadir ., F.I. Barakat ., N.F Abel-Salam, "Kinetics of pyrolysis of olive kernels" IOSR J. Appl. Chem, (2019) 12(4): 50 - 56.

6. G. Omulo ., N. Banadda ., I. Kabenge ., J. Seay, "Optimizing slow pyrolysis of banana peels wastes using response surface methodology" Environ. Eng. Res, 2019, 24(2): $364-361$.

7. M. Agarwal ., J. Tardio ., S.V. Mohan "Biohydrogen production from kitchen based vegetable waste: Effect of pyrolysis temperature and time on catalyzed and non-catalyzed operation” Biores. Tech, 2013. 130: 502 $-509$

8. Y. Qiao ., F. Xu ., X. Ming ., S. Feng ., Y. Ji ., Y. Jiang ., J. Li ., B. Wang , Y. Tian, "Valorization of vegetable waste via pyrolysis: Thermal behavior, volatiles release and products analysis from its extractives" Energy Fuels, available online, Jan. 2020

9. T. Aysu ., M.K Küçüsk, "Biomass pyrolysis in a fixed-bed reactor: Effects of pyrolysis parameters on product yields and characterization of products", Energy 64: 1002 - 1025

10. A. Elorf ., J. Kandasamy ., V. Belandria ., S. Bostyn ., B. Sarh ., E. Gökalp, "Heating rate effects on pyrolysis, gasification and combustion of olive waste", Biofuels. 1-8. 10.1080/17597269.2019.1594598.

11. H. Yang ., R. Yan ., T. Chin ., D.T Liang ., H. Chen ., C. Zheng , "Thermogravimetric analysis-Fourier Transform Infrared Analysis of palm oil waste pyrolysis" Energy Fuels , 2004, 18(6): 1814 - 1821.

12. A. E. Salem., S.S. Younis ., A.A. Shabana ., M.M. Misbah, "Thermal study of date kernels via TG and DTA” J. Therm. Anal, 1989, 35: 2243 $-2254$

13. J. Walyuo ., I. Makertihartha ., H. Susanto (2018) "Pyrolysis with intermediate heating rate of palm kernel shells" AIP Conf. Proc. 1977 (1)

14. R.A Nasser., M.Z. M Salem ., Hiziroglu S., H. A Al-Mefarrej ., A.S Mohareb ., M. Alam ., M.A. Aref, 2016 "Chemical analysis of different parts of date palm (Phoenix dactylifera L.) using ultimate, proximate and thermogravimetric techniques for energy production" Energies 9: 374 379

15. G.I Adhityatama ., F. Hanif ., R.B Cahyono ., M. Hidayat ., T. Akiyama, "A comparative study on pyrolysis characteristic Indonesia biomass and low grade coal", 2017 AIP Conf. Proc. 65.

16. F. Surahmanto ., H. Saptoadi ., H. Sulystio ., T.A Rohmat T.A, "Investigation of the slow pyrolysis kinetics of oil palm solid waste by the distributed activation energy model" Available online in J. Biofuels, 2017 DOI: 10.1080/17597269.2017.1387750. 


\section{Kinetics of Pyrolysis of Date Kernels}

17. M. Hussain ., H. Zabiri ., L.M Tufa ., S. Yusup ., I. Ali, "A Kinetic Study and Thermal Decomposition Characteristics of Palm Kernel Shell Using Model-fitting and Model-free Methods" Available online in J. Biofuels, 2019, DOI: 10.1080/17597269.2019.1642642

18. ASTM C130-05 (2005) "Standard Test Method for Sieve Analysis of Fine and Coarse Aggregates"

19. P. Roura ., j. Farjas , "Analytical solution for the Kissinger equation" J. Mater. Res, 2009, 24: 3095-3098

20. M. Venkatesh ., P. Ravi ., S.P Tewari, "Isoconversional Kinetic Analysis of Decomposition of Nitroimidazoles: Friedman method vs Flynn-Wall-Ozawa Method” J. Phys. Chem. A, 2013, 117(40): $10162-10169$

21. E. Urbanovici ., C. Popescu ., E. Segal, "Improved iterative version of the Coats-Redfern method to evaluate non-isothermal kinetic parameters" J. Therm. Anal. Calorim, 1999, 58: 683-700.

22. A. Khawam .,D.R. Flanagan D.R, "Solid-state kinetic models: basics and mathematical fundamentals" J. Phys. Chem. B, 2006, 110(35): $17315-17328$

23. M.I El Saidy., M.F Abadir., H.H El Sersy ., O.A Ibrahim, "Kinetics of dissolution of clinker components in some aggressive solutions" Int. J. Applied chem, 2007, 3(2): 127 - 132

\section{AUTHORS PROFILE}

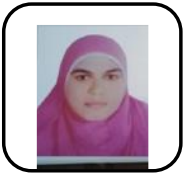

Sohair Taha Aly, Chemical Engineering Department Ph.D. candidate in Faculty of Engineering, Cairo University, Lecturer assistant in Egyptian Academy for Engineering \& Advanced Technology (EA\&EAT), Egypt. I have good experience in different research fields such as, composite materials, solid state kinetics, waste water treatment especially using adsorption techniques. I also acted as supervisor for different research groups of students in the field of renewable energy.

Publications samples:

1. J Therm Anal Calorim (2014) 118:1543-1549 DOI 10.1007/s10973-014-4044-4

2. IJERT(2019) Synthesis and Characterization of ISSN (Online) : 2278-0181,Biodiesel from Waste Cooking Oil and Virgin Oil

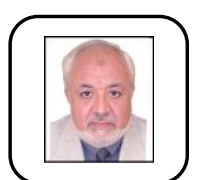

Prof Ibrahim Ahmed Ibrahim Material Science Department,Central Metallurgical Research Institute, Helwan, Egypt. I worked in different research fields as follow:

of metallic/non-metallic values.

- Bio-processing of minerals e.g. sulphide ore, Manganese \&iron ores.

- Pilot plant design and operation.

- Specific experience in area of leaching, flocculation, filtration, washing, evaporation and crystallization.

- $\quad$ Specific experience in processing of bentonites, phosphates, chromites, barrettes, clays and other raw materials.

Publications sample:

1. COMB CHEM HIGH T SCR 2019

DOI:10.2174/1386207323666191217130209

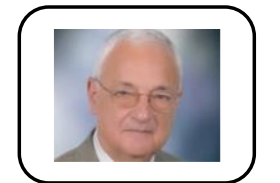

Prof. Magdi Fouad Abadir, Chemical Engineering Department, Cairo University, Egypt. I have published about 85 papers and authored one book (Elements of Ceramic Technology). I was chosen in 2004 among the top 100 world scholars in the field of thermal analysis.

Currently, besides teaching and research, I represent the currently, besides teaching and research, I represent

the Chemical engineering specialty in the meetings of

the Engineering sector affiliated to the Higher

University Council. Besides, I act as coordinator of the

Petroleum and Petrochemical engineering credit Hours Program.

Publication sam

J Therm Anal Calorim (2014) 118:1543-154

DOI 10.1007/s10973-014-4044-4.

2. IOSR-JAC (2019), Volume 12, Issue 4 Ser. I (April. 2019), PP 50-56

DOI: 10.9790/5736-1204015056 